\title{
Comparison of aliphatic hydrocarbon resistant plasticized PVC hoses
}

\author{
Krisztina Roman ${ }^{1}$, Gabriella Zsoldos ${ }^{2}$, Kalman Marossy ${ }^{3}$ \\ ${ }^{123}$ University of Miskolc, B1/214 Miskolc, Hungary, 3515
}

\begin{abstract}
This paper presents an experimental investigation of two types of aliphatic hydrocarbons resistant soft PVC hoses. A number of tests were performed to determine the internal structures and the difference between the hoses. First tests concerned with pentane resistance, the plasticizer and extender's effects on variations in the structure. The solubility of gas in plasticizer and the changing of morphology determined the applicability. The second analysis of FTIR results can show the internal structure's composition, what the difference is between the two formulations. The weight changes of the hoses can shows the material's gas resistance. The gas diffusion's driving force was the gas evaporation. The gas diffusion can be determined from the decrease of the quantity of the hydrocarbons. The internal structure was also observed by DMA. The measurement was made after a pentane soak of simple samples. The morphology, the material's density, mechanical properties and aliphatic hydrocarbon resistance of samples were determined. After all the measurements, the difference between the products was noticeable during even visual inspection of the samples as well.
\end{abstract}

Keywords: PVC hose, FTIR, DMA, gas diffusion, aliphatic hydrocarbon resistant.

\section{INTRODUCTION}

The use of aliphatic resistant PVC hoses is spreading all across the world, with improved gas safety requirements for industry and public facilities, such as in home hoses. Numerous reasons for this growth include environmental protection, excellent mechanical properties, superior aliphatic hydrocarbon resistance abilities and comfort features of PVC hoses. It is important for the hose to remain stable with changing temperature, because portable gas equipments are used them during summer excursions, and also at high mountain climbing as well. The advantage of using PVC hose is the gas resistance.

The PVC (polyviny-chloride) is one of the most widely used polymers in the field of hose systems. However, the PVC resin is only suitable for processing with additives. The additives modify the PVC's morphology and structure, which can be measured by FTIR and DMA methods.

\section{MATERIALS}

Hydrocarbon resistant hose was produced according to own formulation and mixing. For comparison a commercial product was used. This hose is made for LPG. The similarity between the hoses is the aliphatic hydrocarbon resistance; both of them can be used as gas hose. The structures of these polymers are more complex than those, used for other applications. For the simplification of sample identification, from now on the own hose is to be called Hose1, and the other Hose2. Basically the Hose1 includes PVC powder raw material and additives, which are: plasticizer (two types of plasticizer: monomer and polyester), lubricants, stabilizer, nitrile rubber (NBR) and filler. The lubricants and stabilizer are essential for processing. The NBR provides hydrocarbon resistance for the hose two types of plasticizers were used to avoid the separation of the mixture. The ingredients of Hose2 are unknown, but it may be similar in composition.

\section{MeASUREMENTS}

\subsection{Sample preparation}

The commercial hose consists of two layers. The outer layer is common - probably light stabilized PVC; the internal layer is the gas barrier i.e. the hydrocarbon resistant material. In case of the commercial product the layers were mechanically separated.

Own formulation was produced by mixing component with laboratory fluid mixer; roll milled at $170^{\circ} \mathrm{C}$ thereafter compression molded into sheets of $1 \mathrm{~mm}$ thickness.

For the commercial product the compression molded sheets were produced directly from the separated internal layer.

Specimens were die-cut for all measurements from the compression molded sheets. 


\subsection{Fourier transformed infrared spectroscopy (FTIR)}

Fourier transformed infrared spectroscopy analysis and testing identifies chemical compounds in products, polymers, coating and other products. It is suitable for indentifying of additives of PVC and the internal structure and components. The analysis helps to understand materials and products. Indentified are the chemical bonds in the molecule by producing an infrared absorption spectrum. The FTIR analysis can be further used for examining the components of a basic polymer, and the organic pollutants. [1][2]. Measurements were carried out with a Bruker Tensor 27 FTIR instrument in reflection ATR mode.

\subsection{Dynamic Mechanical Analysis}

The Dynamic Mechanical Analysis (DMA) is a thermal analysis method, where during the analysis the elastic behavior of the material can be tested with a periodic load in respect to the function of temperature. Complex elastic modulus can be determined; the usual representation of the results is the storage modulus (E') in logarithmic scale and the mechanical loss factor $(\operatorname{tg} \delta)$ which is the ratio of loss modulus (E') and storage modulus. The method is applicable to examine the mechanical properties of the plastic products. The loss modulus is very sensitive to internal molecular motions therefore it gives information about the internal structure of the material, too. Dynamic Mechanical measurements were carried out with Metravib 1db DMA25 instrument in tensile arrangement at $1 \mathrm{~Hz}$ frequency in the temperature range of $-60^{\circ} \mathrm{C}$ to $120^{\circ} \mathrm{C}$. Heating rate was $2^{\circ} \mathrm{C} /$ minute. [3][4]

\subsection{Gas diffusion method}

Aliphatic hydrocarbon resistant hoses are tested for gas diffusion. During the gas diffusion analysis, the gas transferring ability through the structure of the plastic is determined. The structure depends on the additives especially the plasticizer. If more plasticizer is used, the hoses are more flexible and durable. The Hose2 is same on appearance by visual inspection, but harder at touch.

The gas diffusion testing methods differ a little bit to the permeability testing method. The changes in pentane weight permeability can determine. Measured the weight loss every day, it determined the permeability. If the polymer only transfers little quantities of gas, then the hose is resistant to pentane. If it transfers significant amounts, then determining the gas's quantity is relevant. From the mass change, the materials resistance can be derived. The standard values cannot be exceeded the by measured values. If lots of gas can pass through the polymer, then that is not suitable for gas transferring tube. For measurements I used $1 \mathrm{~mm}$ thickness samples, but in fact the original hose thickness is $19 \mathrm{~mm}$.

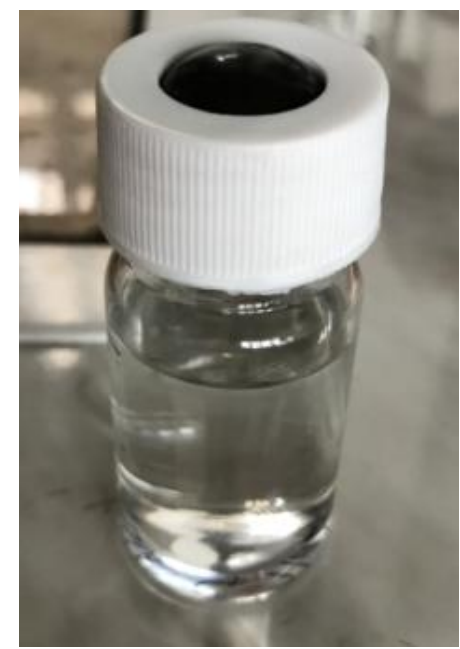

FIG. 1: MEASUREMENT TECHNIQUE

\subsection{Swelling and plasticizer extractability}

Both own formulation and the commercial product were tested by immersion in pentane in order to determine the hydrocarbon uptake and the extractability of plasticizer. Disks of $30 \mathrm{~mm}$ diameter were die-cut from the compression molded sheets and immersed in pentane at room temperature. The laboratory was air-conditioned according to ISO291-23. Room temperature was controlled $23 \pm 1{ }^{\circ} \mathrm{C}$. The full immersion time was 30 days.

Specimen weights were measured daily, exception at the weekends. Extraction causes weight loss, swelling causes increase in weight. 


\section{RESUlT AND DISCUSSION}

\subsection{Fourier transforms infrared spectroscopy (FTIR)}

The internal structure determined by FTIR analysis is shown on Fig 2 . The line 1 presents the Hose 1 product; the line 2 presents the Hose 2 product.

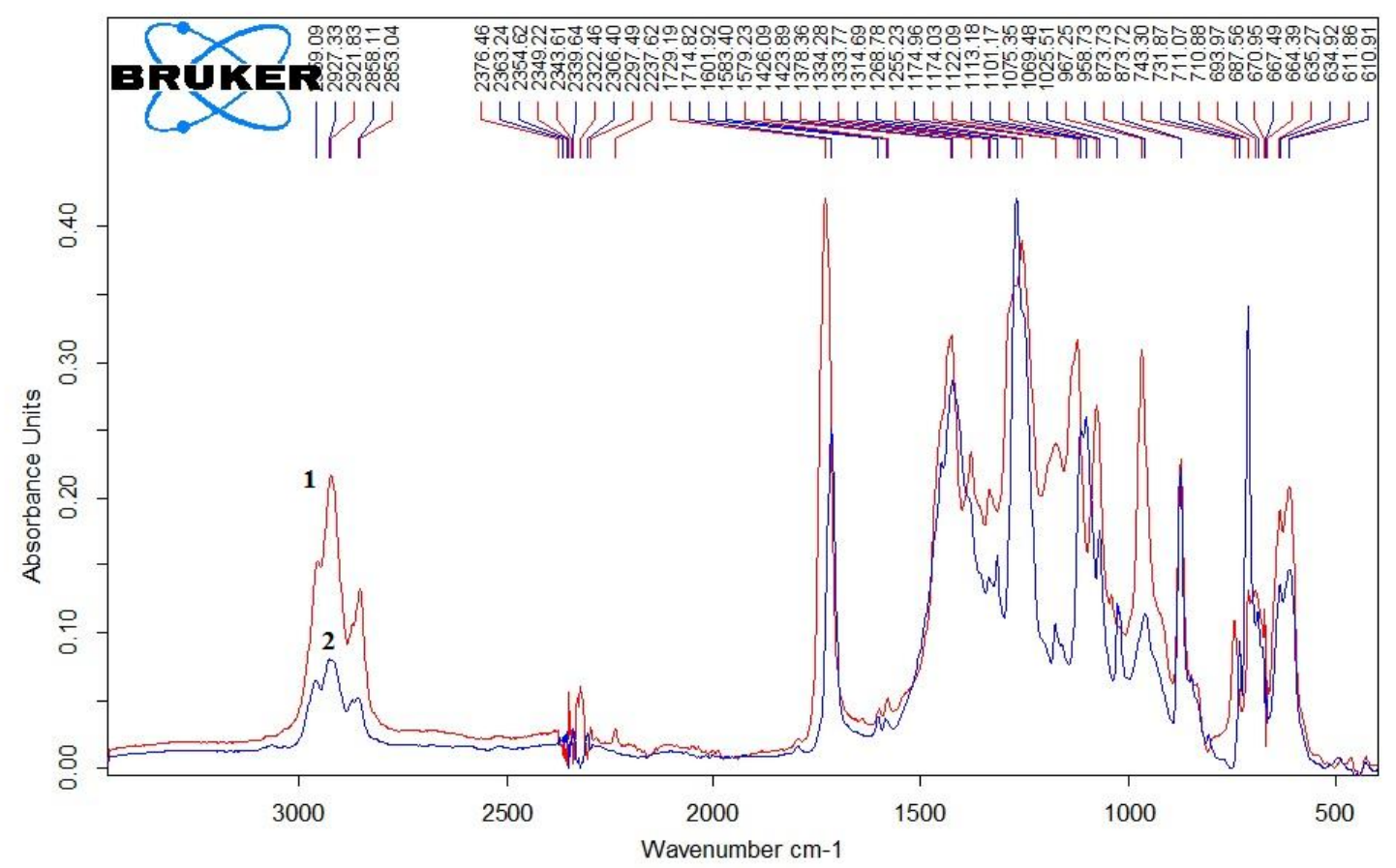

FIG. 2: FTIR ANALYSIS RESULT

All ingredients of the PVC product could be measured. Compared the materials peaks and the product peaks, the products components can be determined.

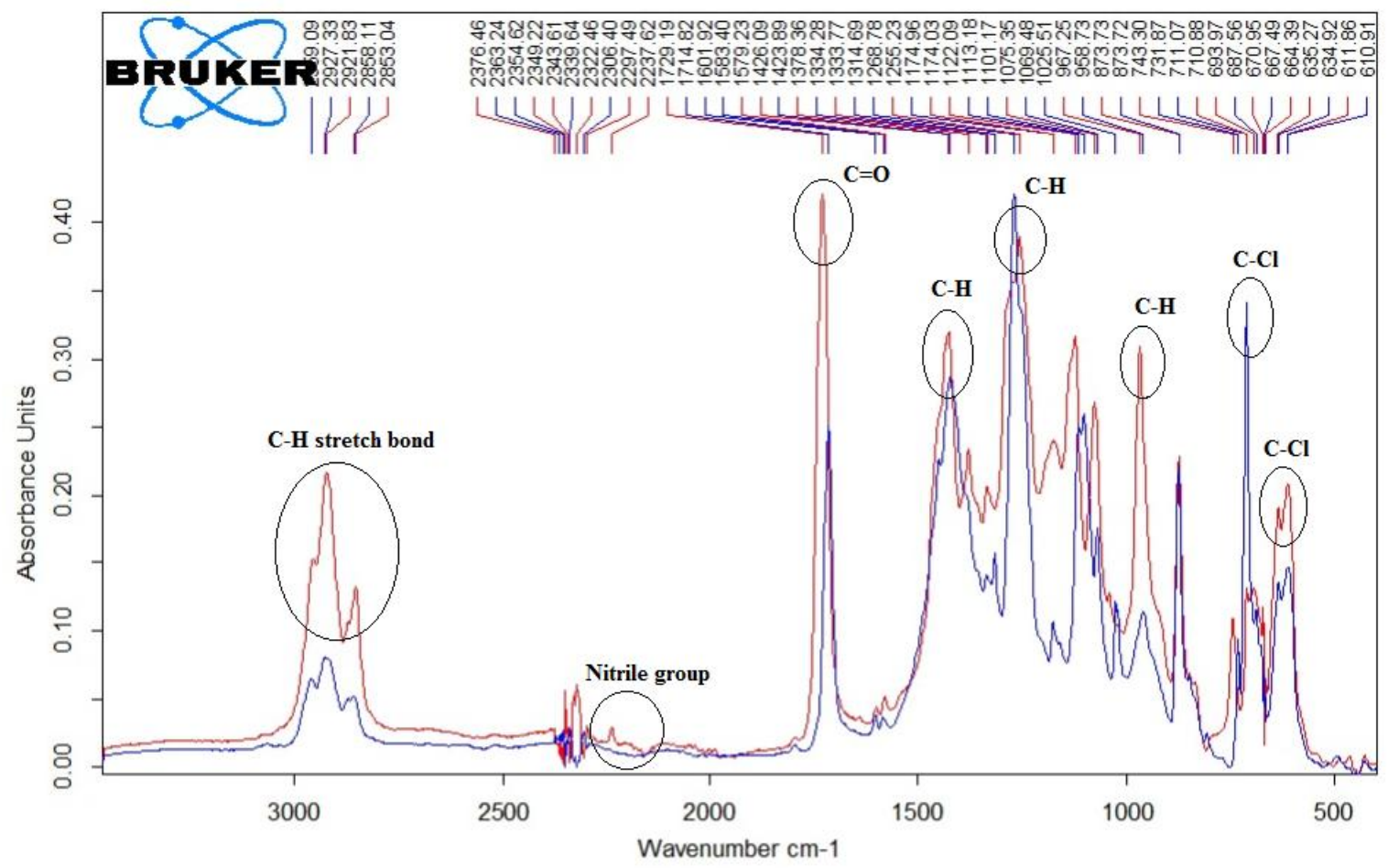

FIG. 3: FTIR ANALYSIS WITH CHEMICAL BONDS 
Fig. 3 shows the chemical bonds and molecules. During the analysis the types of developed bonds can be determined with high precision. Based on the types of bonds and the adherent wavenumber, the additives and the components of the product can be determined. Every additive is measured in order to get the corresponding peaks.

TABLE 1

CONTAIN THE WAVENUMBER WITH ADDITIVES FOR HOSE1

\begin{tabular}{|c|c|}
\hline Wavenumber $\mathbf{~ c m}^{-1}$ & Additives \\
\hline 711 & Filler \\
\hline 743 & Plasticizers \\
\hline 874 & Filler \\
\hline 967 & NBR \\
\hline 1040 & Plasticizers \\
\hline 1255 & NBR \\
\hline 1378 & Plasticizers \\
\hline 1579 & Plasticizers \\
\hline 1729 & Plasticizers \\
\hline
\end{tabular}

The results show that plasticizers and copolymer modifies the ability of the polymer. The most bonds were established by the plasticizer and the applied NBR. The plasticizers modified the overall structure. The FTIR analysis gives basic knowledge about the composition of the product; hence the material's inner structure can be determined also by the relations of the inner bonds.

The FTIR analysis of Hose 2 proves that similar types of additives were used during the production of the hose. The similarity is more outstanding at lower wavelength. Comparing the two measurement results, the difference between the two samples rests in the quantity of the plasticizer and the NBR component, or the difference of the plasticizer.

\subsection{Dynamic Mechanical Analysis}

Hose 1 and Hose 2 samples were measured by DMA. The system gives information about the internal structure and the mechanical loss factor of the samples.
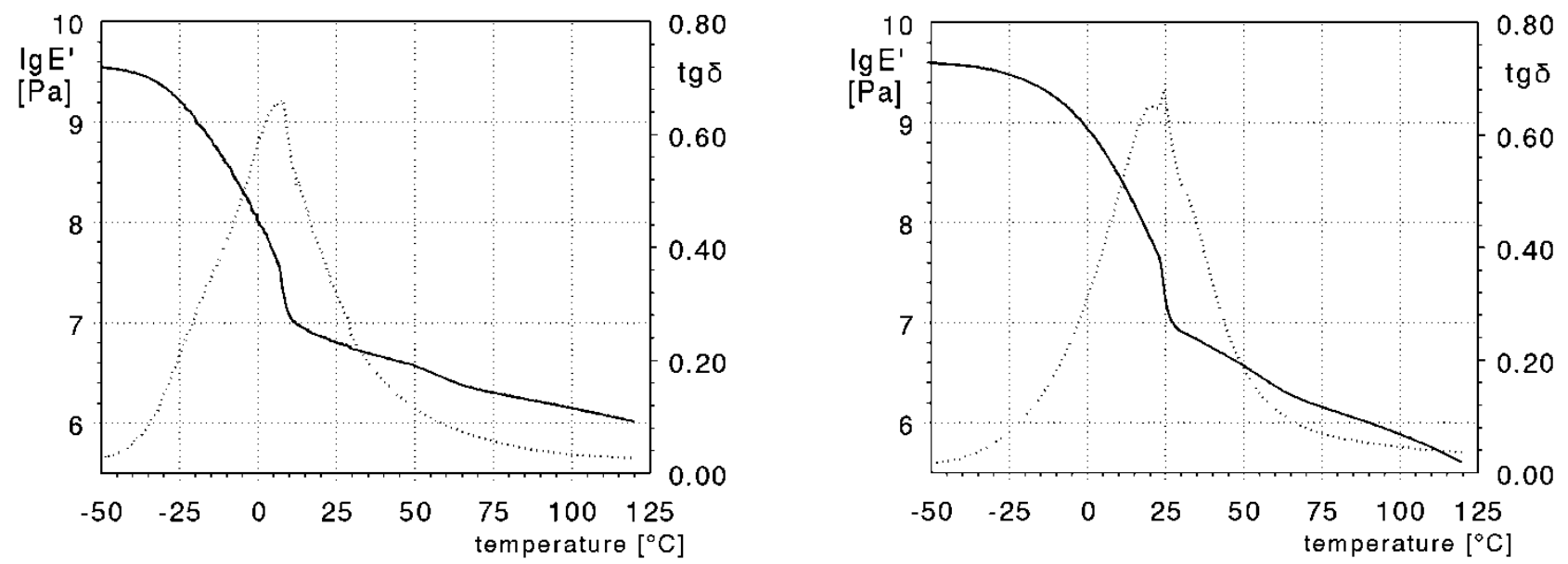

\section{FIG. 4: DMA RESULTS: RIGHT: HOSE1 OWN FORMULATION; LEFT: HOSE2 COMMERCIAL PRODUCT SOLID LINE: STORAGE MODULUS (E'); DOTTED LINE: LOSS FACTOR (tgס)}

Hose 1 and Hose 2 samples were measured by DMA. The system gives information about the internal structure and the mechanical loss factor of the samples. The temperatures of $\operatorname{tg} \delta$ maxima were considered as glass transition temperature. $\operatorname{tg} \delta$ peaks of both materials are not regular proving that a second, partly compatible polymer is present in the composition. Formulation of Hose1 is known, this polymer is the nitrile rubber (NBR). 
The two types of mixtures are very similar. The curves characteristics are similar and they run similar. The E' curve shape is a little bit different from the Hose2. The Hose1 sample is apparently more stable at lower temperatures. The glass transition temperature is lower than that Hose2. The Hose 2 is rigid at the warmer temperature. The result means that the Hose 1 is more resistant and flexible at the lower temperature.

TABLE 2

GLASS TRANSITION TEMPERATURE RESULTS

\begin{tabular}{|c|c|c|}
\hline & Hose1 & Hose2 \\
\hline $\mathrm{T}_{\mathrm{g}}\left[{ }^{\circ} \mathrm{C}\right]$ & 7 & 25 \\
\hline
\end{tabular}

\subsection{Gas diffusion method}

During analysis the value of gas diffusion was matched against the passed time.

Comparing the results it is seen that the gas permeability of Hose1 is slightly higher than of Hose2. Presumably the reasons are the different additives and Hose1 is significantly softer. The softer transferred slightly more gas than the harder. For comparison of the two results linear approximation was made on the measured values. It shows that the Hose 2 is more resistant that the Hose1, but this is because it is harder and contains less plasticizer. Both results are within the permitted limits.

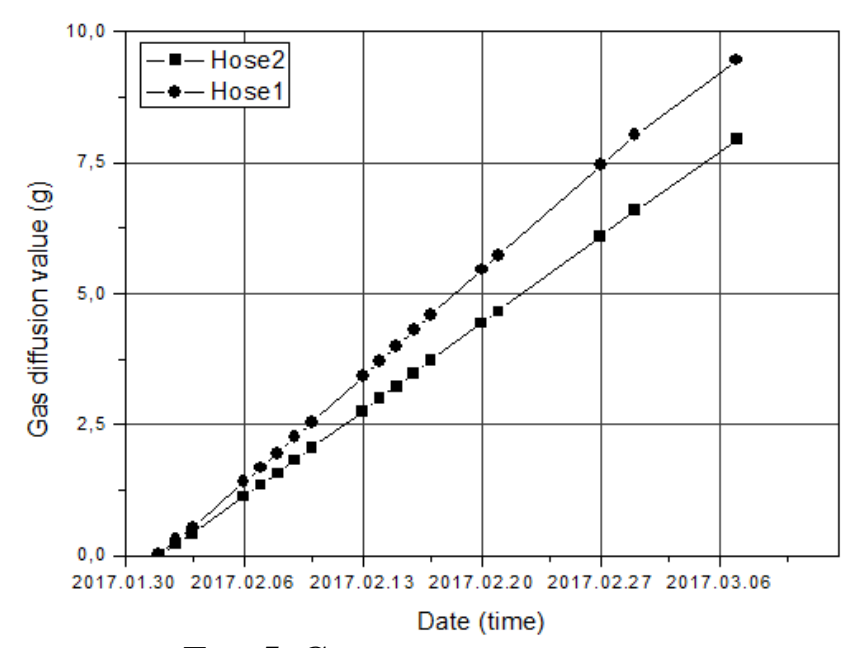

FIG. 5: GAS DIFFUSION RESULTS

\subsection{Pentane resistance measuring method}

The pentane resistance methods were used for analyzing the pentane weight change. Thanks to the alteration, we can gain more insight in to the pentane resistance of PVC mixtures

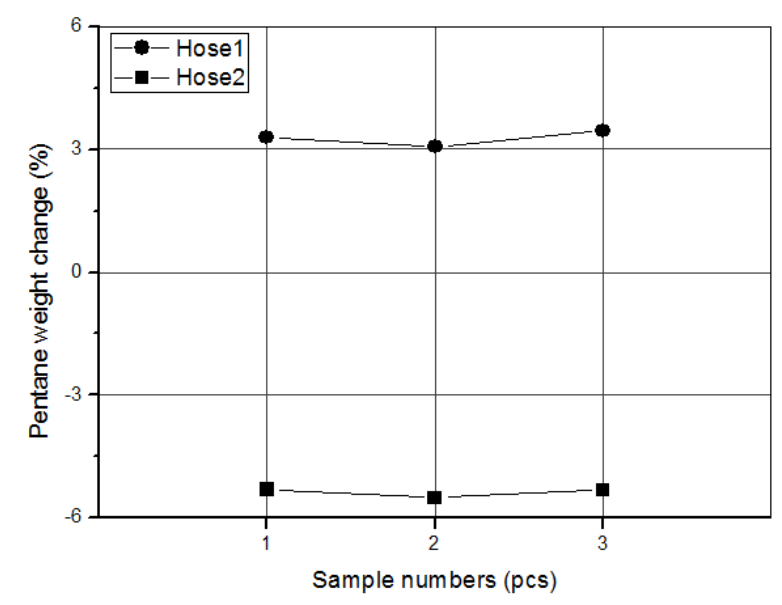

Fig. 6: Pentane Resistance Measuring ReSUlt 
According to the analysis Hose2 was less effective, since the applied plasticizer migrated out of the polymer. Due to the migration of the plasticizer, the mechanical properties of the product will change deteriorate? The properties are worsening because the sample will be harder than the original sample. This means, that Hose 2 is less adequate at low temperature or with larger amount of aliphatic hydrocarbons. The Hose 1 have a plus value that is appropriate, because if the pentane flow disappears, the sample returned to it is original value. During the analysis of Hose1 plasticizer migration did not occur, only the structure of the polymer swelled. From this point of view, the Hose1 is more appropriate.

\section{CONCLUSION}

Overall, the experiments carried out provided useful information on the composition of the two types of hoses. Comparing the tubes mechanical properties the results shows differences. The additives which were used in Hose1 are more resistant to aliphatic hydrocarbons than the Hose 2 ingredients. The most important feature of these types of hoses should be their resistance to aliphatic hydrocarbons.

Both types of hoses are suitable for both industrial and domestic use, but Hose1 was far safer concerning gas release. The slightly better (lower) gas permeability of Hose 2 is caused by lower plasticizer content. It caused the inconvenient hardness of the product. It must also be mentioned, that Hose 2 does not contain real hydrocarbon resistant plasticizer, and this additive is extractable from the product.

It was proved during the analysis, that even small changes in the composition, can cause high impact on the mechanical properties of the product.

\section{REFERENCES}

[1] Kalman Marossy: Testing polymer mixtures by Dynamic Mechanical Analysis, Manuscript of a lecture (2006)

[2] Kalman Marossy: Dynamic Mechanical Analysis, Manuscript of a lecture (2016)

[3] http://www.intertek.com/analysis/ftir/

[4] https://chemistry.oregonstate.edu/courses/ch361-464/ch362/irinstrs.htm 